\title{
First ever guidelines and recommendations on gastrointestinal ultrasound (GIUS)
}

Although there is ample evidence for the clinical use of gastrointestinal ultrasound (GIUS) no guidelines for its practice have previously been published.

Recently, the "EFSUMB Recommendations and Guidelines for Gastrointestinal Ultrasound, Part 1: Examination Techniques and Normal Findings" was accepted for publication in Ultraschall in der Medizin/ European Journal of Ultrasound on 09.08.16. A short version focusing on the recommendations and a long version containing more detailed information was published online 31.08.16.

These recommendations were a result of the work from a task force group in GIUS which was established in October 2014. The task force group consists of international experts of GIUS from 9 European countries recruited through the EFSUMB network with the objective of promoting the use of GIUS in a clinical setting by publishing guidelines and recommendations and starting training networks. They are a part of a guideline-series that also will cover inflammatory bowel disease, transrectal / perineal ultrasound, other inflammatory disorders, functional disorders and miscellaneous pathologies.

This first paper describes the use of different ultrasound modalities in the gastrointestinal tract, presents examination techniques and normal findings in the GI tract and peri-intestinal tissues. Altogether 19 recommendations are presented with level of evidence and grade of evidence. As there is scarce scientific evidence for some the issues included, some of the statements has a level of evidence comparable to expert opinion. Therefore each recommendation was discussed and voted on in a consensus meeting and the degree of consensus reported.

We hope you will find these guidelines and recommendations helpful in your clinical work and an inspiration for future research.

On behalf of the GIUS Task Force Group,

Dr. Kim Nylund, and Prof. Odd Helge Gilja Bergen, Norway 